\title{
Demonstration of a virus-like agent contaminating material containing the Stockholm substrain of the Nichols pathogenic Treponema pallidum
}

\author{
H. GUDJÓNSSON, * B. NEWMAN, AND T. B. TURNER \\ From the International Treponematosis Laboratory of the Department of Microbiology, The Fohns Hopkins \\ University School of Medicine, Baltimore, U.S.A., and the Department of Occupational Dermatology, \\ Karolinska Sjukhuset, Stockholm, Sweden
}

For several years it has been noted in Scandinavian laboratories by the senior author and others that inoculation of rabbits with material containing the Nichols strain of Treponema pallidum often led to an acute febrile disease with high mortality (Gudjónsson and Skog, 1968a, 1970; Jörgensen, 1968; Hederstedt, 1968). This became particularly evident when an attempt was made to study the Jarisch-Herxheimer reaction in rabbits to obtain answers to questions suggested by clinical studies (Skog and Gudjónsson, 1966; Gudjónsson and Skog, 1968b). This Stockholm substrain of the Nichols pathogenic T. pallidum had originally been obtained from the Johns Hopkins laboratory in 1953 via the State Serum Institute in Copenhagen, and had been maintained in serial passage or in dry ice since that time.

This febrile syndrome has been described in detail by Gudjónsson and Skog (1968a, b, 1970).

Inoculated rabbits developed high fever within 2 to 3 days, and the fever persisted for 5 to 10 days in the animals that survived. Furthermore, about 50 per cent. of the inoculated animals died spontaneously on the third or fourth day after inoculation, although in a few instances death was delayed until the 12 th to 14 th day. Neither the fever reaction nor the mortality rate seemed to be affected by considerable variation in the size of inoculum and the number of treponemes. The reaction and mortality were also the same whether the treponemes had been killed in different ways, by heating, penicillin treatment of the rabbits before and in the days following inoculation, or by density gradient centrifugation. Treatment of the rabbits with corticosteroids did not prevent the reaction, nor did daily intravenous injection for 4 to 7 days of 3 to $5 \mathrm{ml}$. serum from rabbits that had survived the reaction convey any protection (Gudjónsson and Skog, $1968 \mathrm{a}, \mathrm{b})$. The fever reaction could not be induced

Received for publication May 28, 1970

These studies were supported in part by a grant from the World Health Organization, The Whitehall Foundation, and the Karolinska Institute, Stockholm

* Present address: Department of Dermatology, Karolinska

Sjukhuset, S- 104 01, Stockholm 60, Sweden by repeating the inoculation, and no mortality was observed in animals which had reacted on the first inoculation, suggesting that immunity to the agent had developed (Gudjónsson and Skog, 1968a, b, 1970).

Inoculation with the filtrate of a treponemecontaining testicular suspension after passing through a Seitz filter No. QEKS II failed to induce fever or spontaneous deaths. The filtrate was free from treponemes.

The above-mentioned investigations were performed at the Karolinska Hospital in Stockholm using more than 200 rabbits of different breeds; the reaction in previously uninfected rabbits was essentially the same in all animals.

The increasing mortality rate in rabbits used for the TPI reaction when using frequent passages of Nichols strain of $T$. pallidum has been reported from other laboratories in Scandinavia by Jörgensen in Copenhagen (1968), Hederstedt in Stockholm (1968), and Ericksen in Oslo (reported in discussion in Jörgensen's paper, 1968).

As no fever reaction and no mortality in rabbits after inoculation with the Nichols strain of $T$. pallidum had been reported from the U.S.A. laboratories, it was decided to repeat some of these experiments in the International Treponematosis Laboratory of the Department of Microbiology, at the Johns Hopkins University School of Medicine.

The purposes of these experiments were to determine whether the observations could be repeated using Baltimore-area rabbits, to make careful temperature readings using Baltimore-area rabbits, to make careful temperature readings on animals inoculated with the Baltimore substrain of Nichols $T$. pallidum, and if possible to identify the feverinducing agent in the Stockholm material.

\section{Material and methods}

RABBITS

New Zealand albino male rabbits were used. The weight when starting the experiments varied between $2 \cdot 7$ and $4.9 \mathrm{~kg}$. (average $3.5 \mathrm{~kg}$.). The animals were kept in 
separate cages. They were fed with antibiotic-free pellets and had free access to water. As in the earlier experiments, animals were customarily kept in the laboratory for about a week for observation before inoculation. No symptoms of disease, such as weight loss, diarrhoea, or evidence of respiratory infection, were observed during the pre-inoculation period. Serological tests for syphilis (RPR and FTA) were negative in all rabbits used.

SOURCE, MATERIAL, AND METHODS OF INOCULATION

Two different substrains of Nichols pathogenic T. pallidum were used.

(1) The Stockholm substrain was obtained from the National Bacteriological Laboratory, Stockholm. This substrain had originally been obtained from the Johns Hopkins Laboratory in 1953 via the State Serum Institute in Copenhagen, and had been propagated mostly by testicular transfer from rabbit to rabbit. The material used in initiating the experiments reported here consisted of a whole rabbit testis containing many $T$. pallidum organisms which had been stored in dry ice since November, 1968, and had then been shipped in dry ice from Stockholm to Baltimore in January, 1970. When an emulsion of this material was made in Nelson medium, it contained $1.8 \times 10^{8}$ treponemes per $\mathrm{ml}$. by darkfield microscopy. No motile treponemes were observed, although one surviving rabbit inoculated with this material developed typical syphilitic orchitis in which numerous $T$. pallida were demonstrated by darkfield microscopy some 6 weeks after inoculation.

(2) The Baltimore substrain used in these experiments was from a pool of rabbit testicular emulsion prepared by Dr. Paul Hardy and Miss Ellen Nell (Pool 38) which had been maintained in liquid nitrogen since October, 1969. It contained approximately $1 \times 10^{6}$ treponemes per $\mathrm{ml}$. and was highly infective for rabbits.

The initial passage of the Stockholm strain in Baltimore was made with the testicular material shipped from the National Bacteriological Laboratory, Stockholm. Subsequent passages were made with either testicular emulsions, pleural fluid, or emulsions of pulmonary tissues of rabbits dying with the febrile disease. Testicular and pulmonary emulsions and pleural fluid were centrifuged at 2,000 r.p.m. for $3 \mathrm{~min}$. to sediment cells, and the supernate was used for source material.

\section{TEMPERATURE MEASUREMENTS}

Animals were routinely maintained in a temperaturecontrolled room in which the temperature varied only slightly from $15^{\circ} \mathrm{C}$. Rabbit temperatures were recorded in the same manner as previously described (Gudjónsson and Skog, 1968a, b, 1970) using an ordinary rectal thermometer. Rabbit temperatures were generally taken between 9 a.m. and 9 p.m. and were always taken at least three times. Base-line temperatures were established for at least 3 days before inoculation. Temperatures of $39.5^{\circ} \mathrm{C}$. or higher were scarcely ever observed before inoculation or during the day of inoculation, and temperatures of this level or higher were regarded as probably signifying infection with the Stockholm agent: temperatures of $40 \cdot 2^{\circ} \mathrm{C}$. or above reflect severe disease.

\section{Experimental results}

\section{INOCULATION WITH THE STOCKHOLM SUBSTRAIN OF} NICHOLS PATHOGENIC $T$. pallidum

The results are summarized in the Table. Nine rabbits were inoculated in one testis with $0.5 \mathrm{ml}$. of a suspension prepared in Nelson medium from the original testis shipped from Stockholm. The inoculum contained $1 \times 10^{6}$ treponemes per $\mathrm{ml}$. On the third day after inoculation all animals had fever of $39.5^{\circ} \mathrm{C}$. or above and in six the temperature rose to $40 \cdot 2^{\circ} \mathrm{C}$. or above. Several rabbits had hypothermia shortly before death. Six rabbits died on the 5th day and one was killed just before expected death. Autopsy showed the typical gross pathology as previously noted (Jörgensen, 1968; Gudjónsson and Skog, 1970), congestion and haemorrhage in the lymph nodes, congestion of the lungs, and slightly haemorrhagic fluid in each pleural cavity. The inoculated testis usually appeared to be normal. Details of the gross and microscopic histological findings will be presented in a subsequent paper (Squire, Small, Strandberg, and Gudjónsson, to be published).

These rabbits of the Baltimore stock thus showed essentially the same clinical and gross pathological

TA BLE Febrile disease in Baltimore rabbits inoculated with the Stockholm substrain and Baltimore substrain of Nichols pathogenic T. pallidum

\begin{tabular}{|c|c|c|c|c|c|c|}
\hline \multicolumn{2}{|l|}{ Inoculation } & \multirow{2}{*}{ No. of rabbits } & \multicolumn{2}{|c|}{ Number with fever $\left({ }^{\circ} \mathrm{C}.\right)$} & \multicolumn{2}{|r|}{ Deaths } \\
\hline First substrain & Test substrain & & $39 \cdot 5+$ & $40 \cdot 2+$ & No. & Days \\
\hline None & $\begin{array}{l}\text { Stockholm } \\
\text { First passage } \\
\text { Subsequent passage } \\
\text { Testicular tissue } \\
\text { Pleural or pulmonary tissue }\end{array}$ & $\begin{array}{l}9 \\
6 \\
8\end{array}$ & $\begin{array}{l}9 \\
6 \\
8\end{array}$ & $\begin{array}{l}6 \\
3 \\
6\end{array}$ & $\begin{array}{l}6 \\
5 \\
5\end{array}$ & $\begin{array}{l}5 \\
3-5 \\
3-8\end{array}$ \\
\hline None & Baltimore & 12 & 5 & 1 & 0 & - \\
\hline Nichols, Baltimore & Stockholm & 12 & 7 & 0 & 0 & - \\
\hline
\end{tabular}


picture observed in Scandinavian rabbits inoculated with the Stockholm material.

\section{Second passage}

Emulsions from the testis inoculated in the first passage and from pleural fluid from one rabbit that had died spontaneously on the 5 th day were used for the second passage.

One $\mathrm{ml}$. of the pleural fluid was inoculated into one testis of four rabbits and a testicular suspension in saline into four rabbits. Darkfield microscopy of both testicular suspension and pleural fluid showed no treponemes after long search.

In the second passage the reaction came earlier, especially in the rabbits inoculated with the pleural fluid. All had high fever on the second day. On the third day one of the rabbits inoculated with the testicular tissue and on the fourth day one of the rabbits inoculated with the pleural fluid died. Of eight rabbits in the second passage, six died on the third to the eighth day, in each instance showing much the same clinical picture as described. It was noted however, that rabbits surviving beyond the fifth day often developed signs of generalized muscular weakness, whether because of neuromuscular pathology or severe inanition has not been determined.

\section{Third and fourth passages}

Two rabbits were inoculated with testicular suspension and two with pleural fluid, both from secondpassage rabbits. No treponemes could be found by darkfield microscopy in either the testicular suspension or pleural fluid. All four rabbits developed high fever on the second and third days and three died by the fifth day.

From one of these rabbits an emulsion of involved lung tissue was made and passed by intratesticular inoculation to two rabbits. One third-passage rabbit was killed when in a moribund state on the eighth day and showed typical signs of the disease at autopsy; the other survived.

It was clear from these experiments that rabbits obtained in the Baltimore area were just as susceptible to the Stockholm 'agent' as were rabbits bred in Scandinavia.

\section{INOCULATION OF THE BALTIMORE SUBSTRAIN OF} NICHOLS $T$. pallidum

The first six rabbits were inoculated in one testis with $5 \times 10^{6}$ treponemes in $0.5 \mathrm{ml}$. Nelson medium. Five rabbits developed a temperature of $39.5^{\circ} \mathrm{C}$. and in one the temperature rose to $40 \cdot 2^{\circ} \mathrm{C}$. There were no deaths. All rabbits developed typical syphilitic orchitis on the 14th to 17th day in which motile treponemes were demonstrated by darkfield microscopy.

The rise in temperature was unexpected but may have been significant in view of the findings reported in the next section of this paper.

Later, six other rabbits were inoculated with the same pool of the Baltimore substrain, but while all animals showed slight elevation of temperature it did not reach $39 \cdot 5^{\circ} \mathrm{C}$. in any of them.

CHALLENGE WITH THE 'STOCKHOLM SUBSTRAIN' OF RABBITS PREVIOUSLY INOCULATED WITH THE 'BALTIMORE SUBSTRAIN' OF NICHOLS PATHOGENIC T. pallidum

As reported in an earlier paper by Gudjónsson and Skog (1970), rabbits that had showed the typical fever reaction and had survived a first inoculation were fever resistant and did not succumb when challenged again with the 'Stockholm substrain'. It was somewhat surprising to find that rabbits inoculated with the 'Baltimore substrain' 3 to 4 weeks earlier were resistant to challenge with the 'Stockholm agent'.

Four rabbits inoculated with the 'Baltimore substrain' were re-inoculated with the original Stockholm testicular suspension on the 32nd day after the primary inoculation. At this time all four rabbits showed orchitis and signs of syphilitic infection in the inoculated testis.

The challenge with the Stockholm testicular suspension was made in the same manner as was the original inoculation of the Baltimore rabbits with the Stockholm substrain, including medium and size of inoculum.

Challenge inoculation was made in the testis which had not been inoculated with the Baltimore substrain and which had apparently remained unaffected. Two of the rabbits developed a slight rise in temperature on the third day but the other two had no fever reaction at all. None of the rabbits died (Table). All of three controls developed a febrile reaction and two died.

A second group of rabbits previously inoculated with the Baltimore substrain was challenged with the pleural fluid from a first passage Stockholm substrain animal. Six of the Baltimore substrain animals had originally been inoculated 3 weeks earlier and two 8 weeks earlier. Although all animals in this group had a base-line temperature somewhat higher than normal, presumably due to an active syphilitic orchitis, in only five of the eight did the temperature reach $39.5^{\circ} \mathrm{C}$. and in none did it reach $40.2^{\circ} \mathrm{C}$. and none died. Of four control rabbits inoculated with the same material, all developed fever of $40 \cdot 2^{\circ} \mathrm{C}$. or above, and three died. 
It appeared, therefore, that animals inoculated with the Baltimore substrain had become resistant to the fever-inducing agent in the Stockholm material, although they had shown only minimal evidence of a febrile disease as a result of the primary inoculation.

\section{TITRATION OF INOCULUM}

Pleural exudate was collected from several rabbits, in the second passage, which died of the disease and this was pooled. Two normal rabbits were inoculated with $0.5 \mathrm{ml}$. of the undiluted pooled material and with each of the following dilutions: $10^{-2}, 10^{-4}, 10^{-5}$, and $10^{-6}$. All inoculated rabbits developed fever of at least $39.5^{\circ} \mathrm{C}$. and all but two fever of $40 \cdot 2^{\circ} \mathrm{C}$. or higher. Only one rabbit survived beyond the eighth day; this one (inoculated with the $10^{-6}$ dilution) became ill on the sixth day but survived until the 21st day. The pooled exudate, therefore, contained not less than $2 \times 10^{-6}$ infective units per ml., although the end-point was not reached in this titration.

\section{NEUTRALIZATION OF STOCKHOLM AGENT WITH CONVALESCENT SERUM}

A rabbit surviving the first Baltimore passage of the Stockholm substrain was bled four weeks after infection. No sign of syphilitic infection was present. In vitro neutralization of the Stockholm agent was attempted by adding equal parts of this rabbit's serum to the undiluted testicular emulsion prepared for the first Baltimore passage of the Stockholm material. The mixture was allowed to stand at room temperature for $90 \mathrm{~min}$. and $0.5 \mathrm{ml}$. was then inoculated into one testis of each of three rabbits. Three other rabbits were inoculated with testicular suspension which contained normal saline instead of convalescent serum as diluent. All rabbits in both groups developed fever of $39.5^{\circ} \mathrm{C}$. or higher and two of three rabbits of each group died by the fifth day.

This procedure was repeated using the serum of another rabbit which had survived the original inoculation of the Stockholm material, except that a $10^{-2}$ dilution of pleural fluid was used. Of four rabbits receiving the mixture containing convalescent serum, all developed fever and two died; three of the controls died and the febrile reaction in the controls seemed to be somewhat more pronounced than in the test animals. It must be concluded that no clear-cut neutralization of the Stockholm agent by convalescent serum was demonstrated.

\section{SUSCEPTIBILITY OF OTHER ANIMAL SPECIES}

The senior author had previously inoculated twenty hamsters intratesticularly with an emulsion of the Stockholm material known to produce the febrile syndrome in rabbits. All hamsters remained unaffected.

In the Baltimore laboratories, twelve white Swiss mice were inoculated intraperitoneally and six intracerebrally with material known to produce lethal disease in rabbits. None showed evidence of disease within eight weeks.

Six young adult guinea-pigs were inoculated intraperitoneally with material containing the Stockholm agent in amounts shown to be lethal for rabbits. All these guinea-pigs remained unaffected during a 60 -day observation period.

\section{Discussion}

It is clear from the observations reported here and from previous reports from a number of Scandinavian laboratories that rabbit testicular material containing the Nichols strain of $T$. pallidum currently in use in Scandinavia carries an agent which produces a disease picture in rabbits quite different from that commonly produced by the Nichols strain in laboratories elsewhere. One of the first questions that arose was whether rabbits bred and reared in Scandinavia had some peculiar susceptibility to the Nichols strain of $T$. pallidum, or alternatively, whether rabbits elsewhere were unusually resistant to some effects of this agent.

It is evident from the results reported above that rabbits bred in the Baltimore area are just as susceptible to the 'Stockholm agent' as are Scandinavian rabbits, the clinical picture of the disease being the same in both groups.

Greatest interest attaches to the nature of this Stockholm agent. Is it the result of a mutation of the Nichols strain of $T$. pallidum originally obtained from Baltimore or are these unusual effects due to an agent which is wholly distinct from the Nichols strain of $T$. pallidum? The evidence is virtually conclusive from the evidence reported here and that to be reported later (Aurelian) that the latter situation obtains.

It has previously been suggested that this syndrome might be caused by a hypersensitivity reaction (Jörgensen, 1968) or by some toxic component of the treponemes (Gudjónsson and Skog, 1970). Both of these possibilities appear to be remote. Over the years hundreds of rabbits have been inoculated and reinoculated with syphilitic rabbit material without the induction of this syndrome, or indeed without any evidence of allergic reaction whatsoever.

The syndrome of high fever within the first week after inoculation, a high mortality rate with haemorrhagic lymphatic organs, and extensive pulmonary involvement with hydrothorax, and at times neurological lesions, has been produced by the inoculation of 
materia $_{l}$ in which there is only the remotest possibility of $T$. pallidum being present. Not only were no treponemes found after diligent search in inocula after the first passage, but the syndrome has been produced by three serial passage of pleural fluid after intervals of 4 to 6 days. Clearly, multiplication of the causative agent had occurred. Rabbits surviving inoculation of symptom-inducing pleural fluid have shown no evidence of syphilitic infection after 60 days.

The Stockholm agent has not yet been clearly indentified, although the studies in progress in the Division of Laboratory Animal Medicine at Johns Hopkins University by Aurelian and her associates are promising. There is no evidence of bacterial infection as determined by staining and culture methods, and an agent which induces a cytopathogenic effect in primary rabbit kidney cells in vitro has been isolated from liver and testis tissue of one of the inoculated rabbits and carried through at least five passages in vitro. Moreover, the short incubation period of the disease in rabbits in the absence of bacteria and the early induction of a high degree of immunity in recovered animals are additional factors pointing to the likelihood that the Stockholm agent is a virus.

It may be that this agent is related to Virus III originally described by Rivers and Tillett (1923) and subsequently investigated by number of workers, including Andrewes and Miller (1924), Andrewes (1940), Topacio and Hyde (1932), and more recently Nesburn (1969). Virus III appears to belong to the herpes group of viruses, but seems to be highly specific for the rabbit species. The Stockholm agent likewise seems to be highly specific for rabbits among the common laboratory animals, since we have been unable to induce disease in guinea-pigs and mice, and one of us (H.G.) working in Stockholm has been unable to induce disease in hamsters. Some of the characteristic features of Virus III infection, as described by Andrewes (1940) and earlier authors mentioned above (Rivers and Tillett, 1923: Andrewes and Miller, 1924; Topacio and Hyde, 1932), such as acute orchitis and inclusion bodies in the infected tissues, have not so far been observed in our studies. Furthermore, Nesburn (1969) found that heating the virus he isolated to $50^{\circ} \mathrm{C}$. for $10 \mathrm{~min}$. was sufficient for inactivation. As described by Gudjónsson and Skog (1970), heating the Stockholm agent to $56^{\circ} \mathrm{C}$. twice for $30 \mathrm{~min}$. did not prevent the reaction. Clearly, definitive characterization of the Stockholm agent remains to be accomplished.

Of considerable interest are the observations pointing to the possible existence of the same agent in at least some of the rabbit material in Baltimore containing the Nichols strain of $T$. pallidum, as evidenced by the occurrence of slight fever in rabbits within the first few days after inoculation of this material and the subsequent solid immunity to the Stockholm agent of these inoculated animals.

One can only speculate on the origin of the Stockholm agent, or virus, as it may legitimately be designated. Virus III, or Herpes simplex cuniculi, as it has been termed in some classification systems (Smith and Conant, 1960; Andrewes and Pereira, 1967), has been isolated a number of times in situations in which rapid passage of tissue from rabbit to rabbit has been made. The virus is obviously a naturally-occurring pathogen of rabbits, but there is no information on the frequency of its occurrence or on its natural mode of transmission. Its recovery in the U.S.A. (Rivers and Tillett, 1923; Nesburn, 1969), in England (Andrewes, 1940), and now possibly in Scandinavia, suggests that the virus is widespread among rabbit colonies. It is quite possible, however, that we are dealing here not with Virus III but with some other natural virus pathogen of rabbits.

Nevertheless, rapid passage of the Nichols strain of $T$. pallidum from rabbit testis to rabbit testis to obtain treponemes for the treponemal immobilization test is precisely the situation in which Virus III or some similar virus would be likely to be picked up and its virulence enhanced by the rapid passage. Whether the virus was present in the material originally forwarded from Baltimore or whether it was subsequently encountered in some local rabbit can probably not be determined at this late date. Nor is it known how widespread is the occurrence of the Stockholm rabbit virus among pools of Nichols strain rabbit material in use elsewhere. It seems possible that the virus might be present for years as a contaminant without its presence being made manifest by enhanced virulence through rapid passage.

More pertinent, perhaps, is the question how the Nichols strain of $T$. pallidum can be freed from this accompanying virus. Several methods suggest themselves, but only experience will show whether any one is effective. Because of the apparent insusceptibility of hamsters and mice, the virus may be 'screened out' by passage of the Nichols strain through these species, although it is possible that the virus might survive in these animals just as does the treponeme in mice.

It is possible, too, that transfer of rabbit lymph nodes long after infection might succeed in screening out the virus, but this again is only conjecture. Leisurely passage of treponemal strains in rabbits seems not to be conducive to activation of Virus III, since this virus has not created a problem in this laboratory as far as rabbit deaths are concerned, although there were brief periods in the 1930s when 
the presence of Virus III among syphilitic rabbits in Baltimore was suspected by one of us (T.B.T.). It will be interesting to see whether material containing other strains of treponemes is similarly contaminated with this virus.

\section{Summary and conclusions}

Experiments were conducted in Baltimore with rabbit testicular material containing the Stockholm substrain of the Nichols strain of Treponema pallidum, which in the Stockholm laboratory of one of the authors (H. G.) had been giving rise to a disease in rabbits characterized by fever and a high mortality. The results of the experiments in Baltimore were as follows:

(1) Baltimore rabbits were equally susceptible to the Stockholm fever-producing and lethal agent.

(2) No such syndrome was induced in rabbits by inoculation of the Baltimore substrain of Nichols strain of $T$. pallidum.

(3) The Stockholm agent was perpetuated through four passages in the apparent absence of $T$. pallidum or other bacteria. The agent was obviously multiplying and was demonstrated in pleural fluid and lung tissue as well as in testicular material.

(4) Guinea-pigs and mice were not susceptible.

(5) Rabbits surviving disease produced by the Stockholm agent were resistant to subsequent inoculation of the agent but serum from convalescent rabbits failed to neutralize the agent.

(6) It is concluded that the Stockholm agent is a virus, a conclusion supported by the demonstration of cytopathogenic effect in rabbit kidney cells in vitro by Aurelian and her co-workers.

(7) On the basis of limited observations, rabbits previously infected with the Baltimore substrain of the Nichols strain of $T$. pallidum developed no disease phenomenon upon challenge with the Stockholm agent, which suggests that the Baltimore substrain may also be contaminated with this virus.

\section{References}

ANDREWes, C. H. (1940) F. Path. Bact., 50, 227. and Miller, C. P., Jr. (1924) f. exp. Med., 40, 789 and Pereira, H. G., (1967) 'Viruses of Vertebrates', 2nd ed. Williams and Wilkins, Baltimore Aurelian, L., et al. Personal communication. Gudjónsson, H., and Skog, E. (1968a) 'Proc. 18th Meeting Scand. Derm. Ass.', Turku, Finland ,-- (1968b) Acta derm.-venereol. (Stockh.), 48, 15
- - - (1970) Brit. F. vener. Dis., 46, 318

Hederstedt, B. (1968) Personal communication

JÖRGENSEN, B. B. (1968) Z. Versuchstierk., 10, 46

Nesburn, A. B. (1969) $\mathcal{F}$. Virol, 3, 59

Rivers, T. M., and TilletT, W. S. (1923) $\mathcal{f}$. exp. Med., 38, 673

Skog, E., and Gudjónsson, H. (1966) Acta derm.venereol. (Stockh.), 46, 136

Smith, D., and Conant, N. F. (1960) 'Zinsser: Microbiolozy', 12th ed. Appleton-Century-Crofts, New York

Seuire, R. A., Small, J. D., Strandberg, J. D., and Gudjónsson, H. To be published

Topacio, T., and Hyde, R. R. (1932) Amer. F. Hyg., 15, 99

Démonstration d'un agent contaminant se comportant comme un virus dans le matériel contenant la sous-souche de Treponema pallidum Nichols pathogène

SOMMAIRE

Des expériences furent entreprises à Baltimore avec du matériel testiculaire de lapin contenant la sous-souche 'Stockholm' de la souche Nichols de Treponema pallidum. Dans le laboratoire de l'un des auteurs à Stockholm (H.G.) cette souche avait entraîné une maladie chez les lapins caractérisée par de la fièvre et une forte mortalité. Le résultat des expériences de Baltimore sont les suivants:

(1) Les lapins de Baltimore se montrèrent également sensibles è l'agent entraînant à Stockholm de la fièvre et des morts.

(2) Un tel syndrôme ne put être reproduit chez les lapins inoculés avec la sous-souche 'Baltimore' de la souche Nichols de $T$. pallidum.

(3) L'agent 'Stockholm' se perpétua à quatre passages malgré l'absence apparente de $T$. pallidum ou de bactéries. Cet agent se multiplia évidemment et fut retrouvé dans le liquide pleural et le tissu pulmonaire aussi bien que dans le matériel testiculaire.

(4) Les cobayes et les souris ne furent pas sensibles.

(5) Les lapins survivant à la maladie produits par l'agent 'Stockholm' furent résistants à l'inoculation ultérieure de ce même agent, mais le sérum des lapins convalescents fut incapable de le neutraliser.

(6) On conclut que l'agent 'Stockholm' est un virus et cette conclusion est corroborrée par les constatations, par Aurelian et coll., d'un effet cyto-pathogène pour les cellules du rein de lapin, in vitro.

(7) Sur la base d'observations limitées, il fut noté que les lapins antérieurement infectés avec la sous-souche 'Baltimore' de la souche Nichols de $T$. pallidum ne réagissent par aucun phénomène pathologique lors de l'inoculation avec l'agent 'Stockholm'; ceci suggère que la soussouche 'Baltimore' peut être aussi contaminée par le virus considéré. 